\title{
Differential expression of selected Arabidopsis resistant genes under abiotic stress conditions
}

\author{
Gagan Kumar Panigrahi', Annapurna Sahoo ${ }^{\dagger}$ \& Kunja Bihari Satapathy* \\ School of Applied Sciences, Centurion University of Technology and Management, Odisha 752 050, India \\ ${ }^{\dagger}$ Contributed equally \\ *Email: kunjabihari.satapathy@cutm.ac.in
}

\section{ARTICLE HISTORY}

Received: 18 April 2021

Accepted: 04 July 2021

Available online: 21 August 2021

\section{KEYWORDS}

Pathogen-associated molecular patterns

PAMP-triggered immunity

Effector triggered immunity Resistant genes

Abiotic

Decapping

\section{ABSTRACT}

The plant immune system is equipped with several defensive layers to evade pathogen attack. One of the primary defense includes plasma membrane-localized receptors explicitly detect conserved pathogen-associated molecular patterns. Transcriptional reprogramming of resistant genes confers PAMP-triggered immunity. Consequently basal immunity is triggered which is primarily mediated by several intracellular nucleotide-binding leucine rich repeat receptors. Subsequently, nucleotide-binding leucine rich repeat receptors sense pathogens and activate another defense response known as effector triggered immunity. Both the PTI and ETI are mediated by resistant genes. Interestingly, the detailed molecular function of resistant genes is not yet fully revealed. Resistant genes are also well involved in non pathophysiological conditions such as during cold stress, heat stress, duration of exposure of light and drought stress. Here, we have reported that the Arabidopsis resistant genes AT1G17600, AT4G14368, AT4G16860, AT5G40910 and AT5G45050 are temperature regulated. We found that the transcript levels of AT1G58400, AT2G14080, AT2G17055, AT3G51560, AT4G16950, AT5G40910 and AT5G45050 were significantly raised for the plant samples grown under short-day conditions. The transcript levels of AT1G17600, AT1G27180, AT1G33560, AT2G14080, AT3G51560, AT4G16860 and AT4G16950 were upregulated for plants grown under drought stress conditions. In Arabidopsis, the transcriptional reprogramming is modulated by decapping protein factors. There was no significant change in the protein level of DCPs. Our results suggest that under abiotic stress conditions, the resistant genes differentially express independent of the decapping event.

\section{Introduction}

Plant immune response activation is based on precise recognition between a plant receptor and a cognate pathogen effector, famously described as gene-forgene relationship among plant host disease resistant genotypes and avirulent pathogenic strains (1). Overall, the plant immune system executes its role via two distinct arms, namely, pattern triggered immunity (PTI) and effector triggered immunity (ETI) (2). Plant immunity, as a counter-attack is elegantly modulated by two diverse immune receptors, commonly known as pattern recognition receptors (PRRs) and intracellular immune receptors, nucleotide-binding oligomerisation domain-like receptors (NLRs). Once the cell surface bound pattern recognition receptors (PRRs) perceive conserved pathogen associated molecular patterns (PAMPs), this sets the stage for onset of primary first line plant defense leading to pattern triggered immunity (PTI) $(3,4)$. With the onset of PTI, several other known defense pathways including, reactive oxygen species (ROS) burst, activation of mitogen activated protein kinases (MAPKs), expression of immune related genes is induced in order to prevent non-adapted pathogens from infecting (5). Another arm of plant immune response, commonly called as effector-triggered immunity (ETI), commonly considered as an amplified version of PTI, is equally vital for provoking an effective response against pathogenic molecules $(6,7)$. With an increasing adaptive nature of pathogens to evade the primary defense system of host plant, they are able to release virulence factors known as effectors into the apoplast or cytoplasm of the host cell. Previous findings have shown that effectors do interfere with the PTI pathway so as to allow pathogens to colonize the host cell and thus leads to effector-triggered susceptibility (ETS) (8). In turn, effector molecules are specifically recognized by intracellular nucleotide binding/leucine rich repeat 
(NLR) receptors resulting to the activation of the ETI $(9,10)$. ETI is essentially characterized by a tightly regulated transcriptional reprogramming followed by a phenotypic event that is, localized plant cell death known as hypersensitive response (HR) (9, 1114). Broadly, PTI mediates moderate disease resistance to a wide range of pathogens, and ETI is accountable for the resistance to any explicit pathogen harbouring a cognate avirulence gene (8, $15,16-20)$. However, the regulatory circuit of the two classes of plant $\mathrm{R}$ genes encoding Toll/interleukin-1 receptor (TIR)-NBS-LRR (TNL) and coiled coil (CC)NBS-LRR (CNL) proteins is yet to be elucidated (21, 22). Interestingly, there are no direct evidences related to the role of $R$ genes under abiotic stress conditions. $R$ genes are also well involved in non pathophysiological conditions such as during cold stress, heat stress, duration of exposure of light and drought stress. In Arabidopsis the transcriptional reprogramming is modulated by decapping protein factors (23-26). In eukaryotes, mRNA turnover primarily involves the elimination of m7GDP from the 5' end. The 5' monophosphate is a substrate for the 5' exonuclease XRN1 resulting in the quick decay of the mRNA. Primarily, a protein complex mediates the decapping reaction. The decapping protein complex is well characterized in yeast and human but not in plants. In Arabidopsis thaliana, DCP1, DCP2, DCP5 are the central decapping protein factors. The $R$ genes play an important role in conferring the plants with the ability to defend themselves against pathogens. Previous studies have confirmed the involvement of these genes in plant immunity under biotic stress condition. But, the fate of these genes has not been revealed under abiotic stress conditions. Abiotic stress majorly includes the environmental abiotic factors(s) which can have a prominent effect on the growth and viability of plants. Under limiting conditions, abiotic stress may have a significant effect on plant physiology by regulating the expression of vital gene(s). Abiotic stress includes heat stress, cold stress, drought stress, salinity stress, light stress and many more. Here, we reported the effect of abiotic stress on the relative expression of $R$ genes.

\section{Materials and Methods}

\section{Plant materials and growth conditions}

Seeds of wild-type Arabidopsis (Arabidopsis thaliana) ecotype Columbia-0 (Col-0) were sown in soil. The plants were grown simultaneously under short-day (12/12 hr light/dark) and long-day (16/8 hr light/dark) conditions at $22{ }^{\circ} \mathrm{C}$ with $70-80 \%$ relative humidity. Western blotting and RNA-seq assays were done using the leaves of Arabidopsis thaliana. The Arabidopsis plants grown under long-day conditions were used for cold stress, heat stress and drought stress experiments. For heat stress assays, the plant samples were incubated at $37{ }^{\circ} \mathrm{C}$ for 10 min. Arabidopsis plants were grown under water deficient conditions for carrying out drought stress assays. Likewise for performing cold stress experiments, plants were grown under $16 / 8 \mathrm{hr}$ light/dark at $16{ }^{\circ} \mathrm{C}$ and $16 / 8 \mathrm{hr}$ light/dark at $4{ }^{\circ} \mathrm{C}$ growth conditions.

\section{RNA-seq}

Fully grown rosettes of three-week-old Arabidopsis plants were used for the RNA-seq analysis. Plant samples to be dipped in $0.5 x$ MS medium, vacuum infiltrated and incubated in the dark for $4 \mathrm{hrs}$. After the RNA purity is confirmed with a bioanalyzer, the total RNA was processed for preparation of the mRNA sequencing (Illumina). $500 \mathrm{ng}$ total RNA to be used to obtain mRNAs. A-tailing and end-repair was done after first and second-strand complementary DNA synthesis. All samples were processed in three biological replicates $(7,23,24)$.

\section{Protein extraction and Western blotting}

Total proteins were isolated from $0.1 \mathrm{gm}$ leaf of the twenty one day old Arabidopsis thaliana Col-0 plants. The leaves were harvested from plants which were grown simultaneously under short-day (12/12 hr light/dark) and long-day conditions (16/8 $\mathrm{hr}$ light/dark) at $22{ }^{\circ} \mathrm{C}$. Similar approach was followed to isolate the total protein from cold stress, heat stress and drought stress induced plant samples. The composition of the extraction buffer was $20 \mathrm{mM}$ of Tris-Cl (pH 8.0), $100 \mathrm{mM}$ of $\mathrm{NaCl}, 1 \mathrm{mM}$ of EDTA, 1 $\mathrm{mM}$ of PMSF and $1 \mathrm{X}$ proteinase inhibitor. Western blot analysis was done using protein-specific antibodies (7).

\section{Results and Discussion}

\section{Differential temperature affects the mRNA levels of Arabidopsis resistant genes}

The defense-related genes in Arabidopsis predominantly are involved in conferring the plants to defend against incoming pathogens. But, their role during abiotic stress is yet to be revealed. In this context, the current study intended to see the behaviour of resistant genes when plants are challenged with heat and cold stress. It was observed that the resistant genes AT1G17600, AT4G14368 and AT4G16860 are highly expressed when plants are exposed to cold stress (16/8 hr light/dark; $16{ }^{\circ} \mathrm{C}$ and $16 / 8 \mathrm{hr}$ light/dark; $4{ }^{\circ} \mathrm{C}$ ) relative to their transcript levels under normal physiological growth conditions (16/8 hr light/dark; $22{ }^{\circ} \mathrm{C}$; Fig. 1). Similarly, when plants were exposed to heat stress conditions $\left(37^{\circ} \mathrm{C}\right.$; 10 min several resistant genes were expressed at a higher level relative to the transcript levels under normal physiological growth conditions (16/8 hr light/dark; $\left.22^{\circ} \mathrm{C}\right)$. The transcript levels of AT5G40910 and $A T 5 G 45050$ were 1.6 times with respect to their counterparts (Fig. 2). The differential expression of Arabidopsis resistant genes under temperature stress reveals that apart from their canonical role; defenserelated genes may also be well involved in supporting the plants to respond to any change in temperature conditions. Changes in cellular homeostasis under different temperature conditions might be manipulated by a set of temperature regulated resistant genes in Arabidopsis.

The duration of exposure of light modulates the expression level of resistant gene transcripts

To validate our assumption that the Arabidopsis resistant genes are regulated by the duration of 


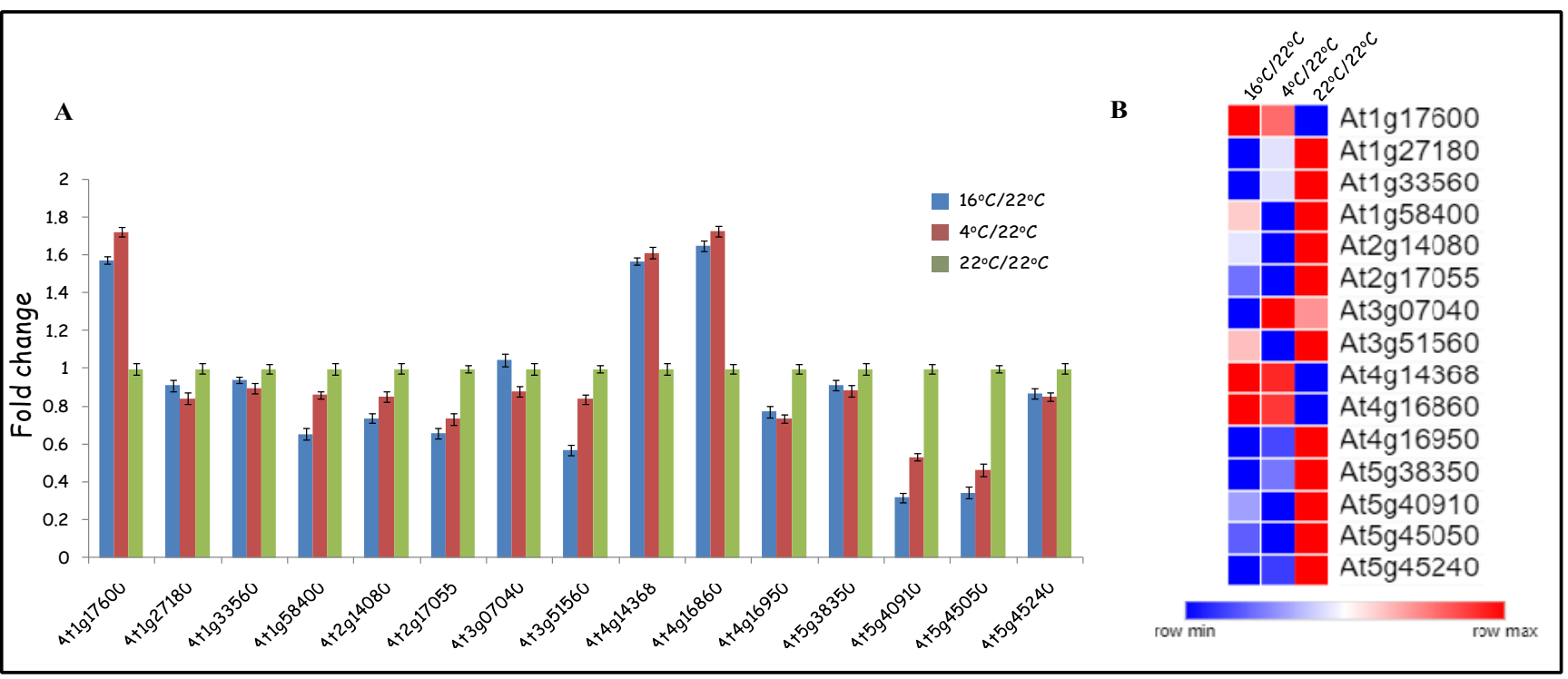

Fig. 1. Differential RNA level expression of the Arabidopsis resistant genes under cold stress. (A) The expression levels of AT1G17600, AT4G14368 and AT4G16860 were upregulated for plants exposed to cold stress. (B) Heat map of differential expression patterns of the Arabidopsis resistant genes under cold stress. Web-based tool Morpheus was used to generate the heat map.

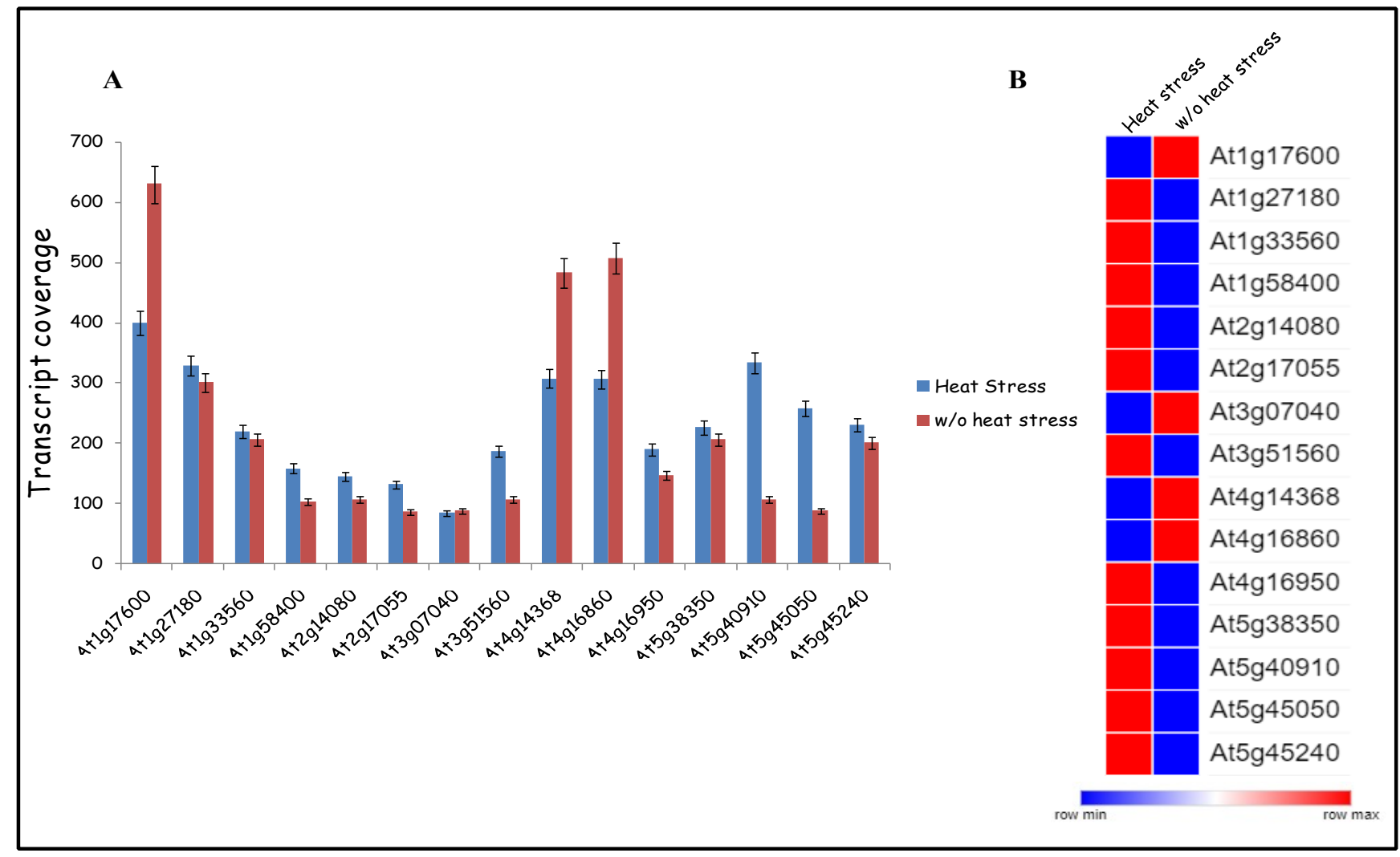

Fig. 2. Differential transcript coverage of the Arabidopsis resistant genes under heat stress. (A) The transcript coverage of AT5G40910 and AT5G45050 were higher for plants exposed to heat stress. (B) Heat map of differential transcript coverage of the Arabidopsis resistant genes under heat stress. Web-based tool Morpheus was used to generate the heat map.

exposure of light, we checked the transcript level of the Arabidopsis defense genes for the plant samples grown at long-day and short-day conditions. Interestingly, we found that the transcript levels of AT1G58400, AT2G14080, AT2G17055, AT3G51560, AT4G16950, AT5G40910 and AT5G45050 were significantly raised for the plant samples grown under short-day conditions relative to their expression levels for plants grown under long-day conditions (Fig. 3). This previously unrevealed fact makes sense in a manner that it represents specific Arabidopsis defense genes which also get involved in nonpathophysiological environment in plants and identifying the detailed role(s) of these specific genes would be intriguing.

\section{Under drought stress conditions, the transcript level of several resistant genes is upregulated}

Similarly when plants were challenged with drought conditions, several Arabidopsis resistant genes were differentially expressed. The transcript levels of AT1G17600, AT1G27180, AT1G33560, AT2G14080, AT3G51560, AT4G16860 and 
AT4G16950 were upregulated for plants grown under drought stress conditions relative to the plants grown under normal physiological growth conditions (Fig. 4). This result hints out that several defense related genes in Arabidopsis are also being involved in molecular events specific to drought stress. The underlying molecular mechanism(s) through which resistant genes participate during drought conditions needs to be revealed. Resistant genes-mediated response of plants during drought stress could be edifying.

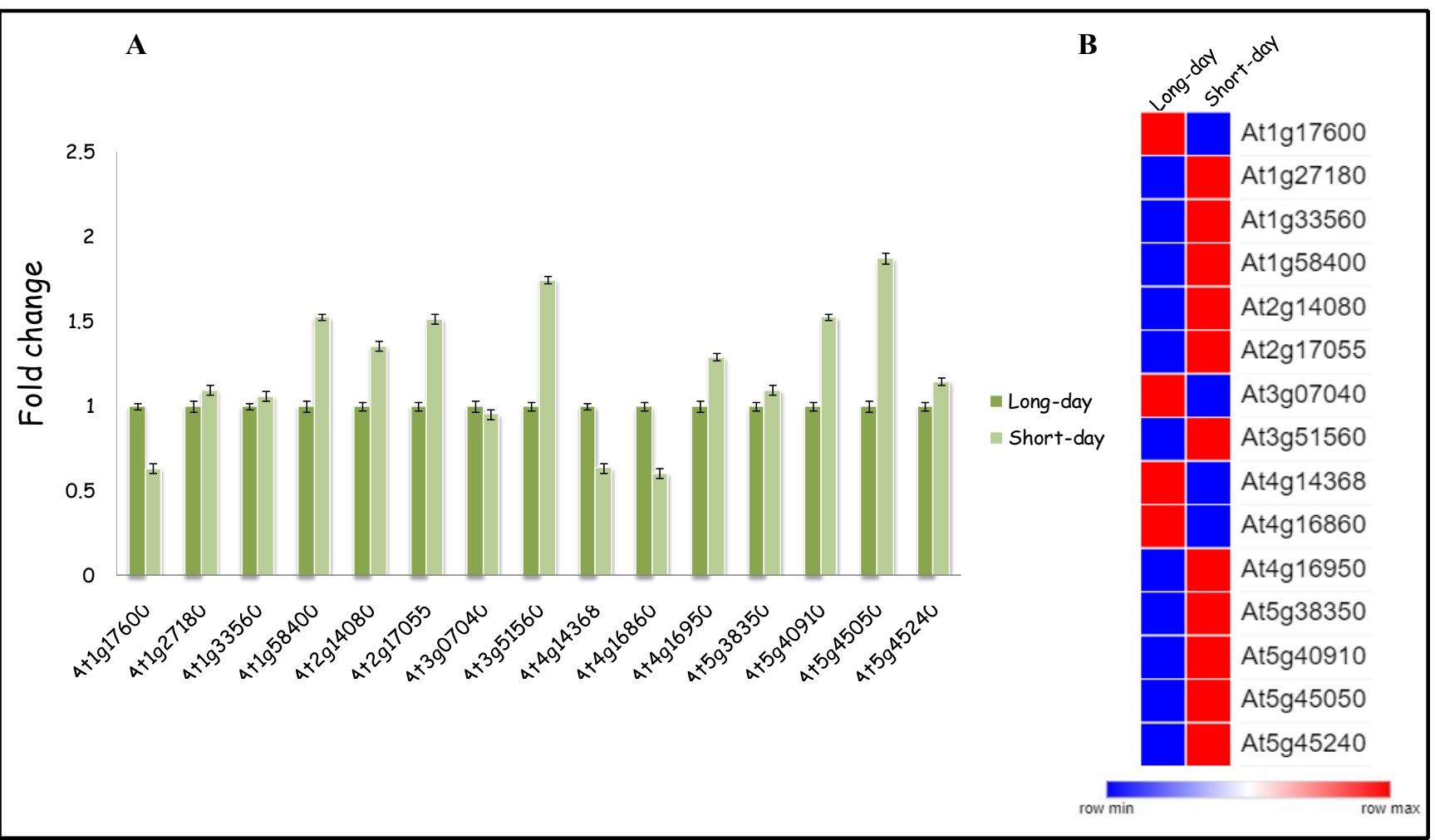

Fig. 3. Differential RNA level expression of the Arabidopsis resistant genes under short-day conditions. (A) The expression levels of AT1G17600, AT4G14368 and AT4G16860 were upregulated for plants grown under short-day conditions. (B) Heat map of differential expression patterns of the Arabidopsis resistant genes under short-day conditions. Web-based tool Morpheus was used to generate the heat map.

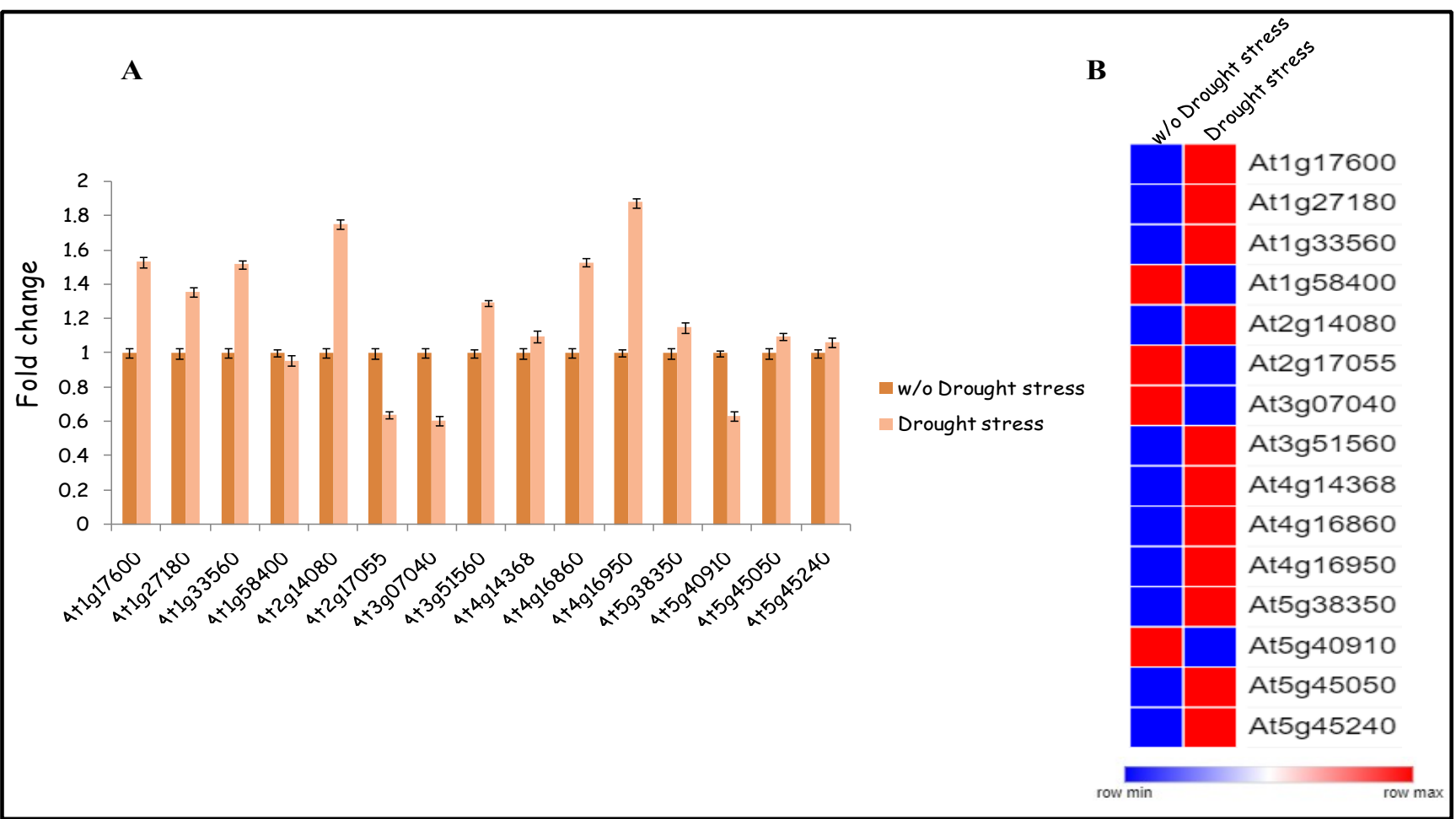

Fig. 4. Differential RNA level expression of the Arabidopsis resistant genes under drought stress conditions. (A) The expression levels of AT1G17600, AT1G27180, AT1G33560, AT2G14080, AT3G51560, AT4G16860 and AT4G16950 were upregulated for plants grown under drought stress conditions. (B) Heat map of differential expression patterns of the Arabidopsis resistant genes under drought stress conditions. Web-based tool Morpheus was used to generate the heat map. 
The protein level of decapping protein factors remains unaffected under abiotic stress conditions

Transcriptional reprogramming depends on several factors. The expression of immune genes under varied abiotic stress conditions would certainly be under strict regulation. One of such regulatory mechanisms that eventually determine the fate of mRNA is the mRNA decapping event, essentially mediated by decapping proteins (DCPs): DCP1, DCP2 and DCP5. To validate whether there is any change in the protein level of the DCPs when plants are challenged with abiotic stress, we performed immunoblotting assays to confirm the protein levels. There was no significant change in the protein level of DCPs (Fig. 5). The protein level of actin was also considered to be the internal control. Equal concentration of protein loading was done as revealed by Ponceau S staining for RuBisCo.

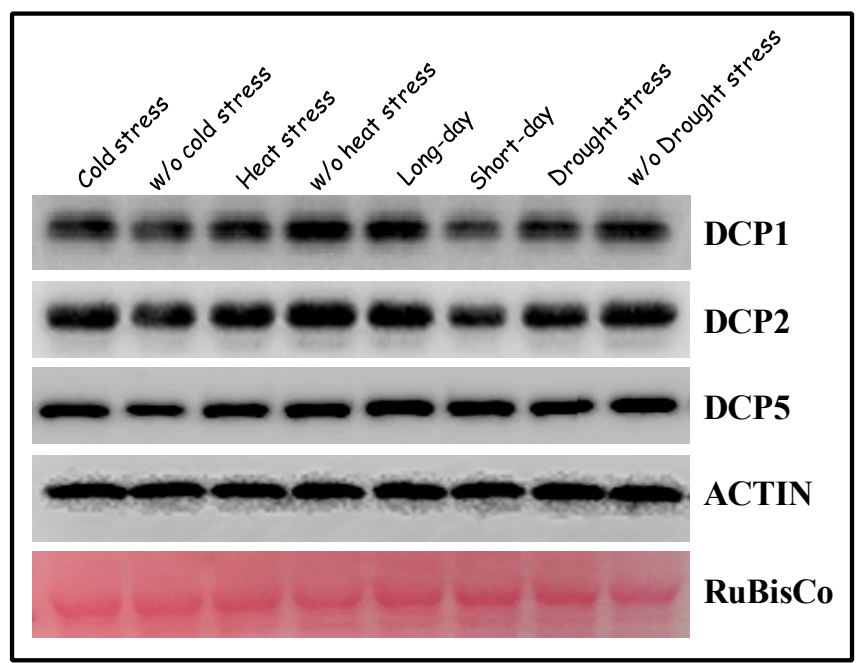

Fig. 5. The protein level of the Arabidopsis decapping protein factors; DCP1, DCP2 and DCP5 remains unaffected under the abiotic stress conditions. The Western blots were generated using proteinspecific antibodies.

\section{Conclusion}

Revealing the functional and physiological role of the Arabidopsis resistant genes is of great interest may unravel many hidden molecular mechanism(s). It was observed that the resistant genes AT1G17600, AT4G14368 and AT4G16860 are highly expressed when plants are exposed to cold stress $(16 / 8 \mathrm{hr}$ light/dark; $16{ }^{\circ} \mathrm{C}$ and $16 / 8 \mathrm{hr}$ light/dark; $4{ }^{\circ} \mathrm{C}$ ) relative to their transcript levels under normal physiological growth conditions (16/8 hr light/dark; $\left.22{ }^{\circ} \mathrm{C}\right)$. Similarly, when plants were exposed to heat stress conditions $\left(37^{\circ} \mathrm{C}\right.$; $\left.10 \mathrm{~min}\right)$ several resistant genes were expressed at a higher level relative to the transcript levels under normal physiological growth conditions (16/8 hr light/dark; $\left.22{ }^{\circ} \mathrm{C}\right)$. The transcript levels of AT5G40910 and AT5G45050 were 1.6 times with respect to their counterparts. Interestingly, we also found that the transcript levels of AT1G58400, AT2G14080, AT2G17055, AT3G51560, AT4G16950, AT5G40910 and AT5G45050 were significantly raised for the plant samples grown under short-day conditions relative to their expression levels for plants grown under long-day conditions. The transcript levels of AT1G17600, AT1G27180, AT1G33560, AT2G14080, AT3G51560, AT4G16860 and AT4G16950 were upregulated for plants grown under drought stress conditions relative to the plants grown under normal physiological growth conditions. These results primarily points out that apart from its canonical function, the resistant genes might be involved in regulating unknown cellular events in Arabidopsis. In animals, resistant genes are well involved in diversified metabolic pathways apart from being involved in defense response. It seems worthwhile to focus on the molecular mechanism(s) through which resistant genes mediates a wide range of physiological events. The detailed mechanism(s) of the resistant genes-mediated events remains to be elucidated. How resistant genes-mediated response is triggered in plants in response to abiotic stress conditions is not yet fully understood. Our results gives a prima facie evidence that the resistant genes are differentially expressed under varied abiotic conditions in Arabidopsis and may be well involved in modulating different physiological processes necessary for the plant to resist the environmental changes.

\section{Acknowledgements}

Authors are thankful to the administration and management of Centurion University of Technology and Management, Odisha, India for providing necessary facilities to conduct the experiment.

\section{Authors' contributions}

GKP conceived the idea, performed the experiments, analyzed the results, wrote the manuscript, have read and approved the final manuscript before submission. AS performed the experiments, analyzed the results, wrote the manuscript, read and approved the final manuscript before submission. KBS conceived the idea, analyzed the results, read and approved the final manuscript before submission.

\section{Conflict of interests}

The authors declare that they have no competing interests.

\section{References}

1. Flor HH. Current status of the gene-for-gene concept. Annual Review of Phytopathology. 1971;9:275-96. https://doi.org/10.1146/annurev.py.09.090171.001423

2. Panigrahi GK, Satapathy KB. Sacrificed surveillance process favours plant defense: a review. Plant Archives. 2020;20(1):2551-59.

3. Böhm H, Albert I, Fan L, Reinhard A, Nürnberger T. Immune receptor complexes at the plant cell surface. Current Opinion in Plant Biology. 2014;20:47-54. https://doi.org/10.1016/j.pbi.2014.04.007

4. Macho AP, Zipfel C. Plant PRRs and the activation of innate immune signaling. Mol Cell. 2014;54(2):263-72. https://doi.org/10.1016/j.molcel.2014.03.028 
5. Boller T, Felix G. A renaissance of elicitors: perception of microbeassociated molecular patterns and danger signals by patternrecognition receptors. Annual Review of Plant Biology. 2009;60 379-406. https://doi.org/10.1146/annurev.arplant.57.032905.105346

6. Panigrahi GK, Sahoo A, Satapathy KB. Insights to plant immunity: Defense signaling to epigenetics. Physiological and Molecular Plant Pathology. 2021;101568:1-7. https://doi.org/10.1016/j.pmpp.2020.101568

7. Panigrahi GK, Satapathy KB. Pseudomonas syringae pv. syringae infection orchestrates the fate of the Arabidopsis J domain containing cochaperone and decapping protein factor 5. Physiological and Molecular Plant Pathology. 2021;101598:19. https://doi.org/10.1016/j.pmpp.2020.101598

8. Jones JD, Dangl JL. The plant immune system. Nature. 2006;444:323-29. https://doi.org/10.1038/nature05286

9. Cui H, Tsuda K, Parker JE. Effector-triggered immunity: from pathogen perception to robust defense. Annual Review of Plant Biology. 2015;66:487-511. https://doi.org/10.1146/annurev-arplant-050213-040012

10. Dodds PN, Rathjen JP. Plant immunity: towards an integrated view of plant-pathogen interactions. Nature Reviews Genetics. 2010;11(8):539-48. https://doi.org/10.1038/nrg2812

11. Panigrahi GK, Sahoo AS. A review on Natural Dye: Gift from bacteria. International Journal of Bioassays. 2016;5(9):4909-12. https://doi.org/10.21746/ijbio.2016.12.0013

12. Panigrahi GK, Sahoo AS, Panda S. A complex network of molecular events triggered upon environmental cues which decide the fate of gene expression: a review. International Journal of Bioassays. 2016;5(12):5185-91. https://doi.org/10.21746/ijbio.2016.12.0013

13. Tsuda K, Glazebrook J, Katagiri F. The interplay between MAMP and SA signaling. Plant Signal Behav. 2008;3(6):359-61. https://doi.org/10.4161/psb.3.6.5702

14. Tsuda K, Sato M, Stoddard T, Glazebrook J, Katagiri F. Network properties of robust immunity in plants. PLOS Genetics. 2009;5(12):1-13. https://doi.org/10.1371/journal.pgen.1000772

15. Chisholm ST, Coaker G, Day B, Staskawicz BJ. Host-microbe interactions: shaping the evolution of the plant immune response. Cell. https://doi.org/10.1016/j.cell.2006.02.008

2006;124(4):803-14

16. Karasov TL, Chae E, Herman JJ, Bergelson J. Mechanisms to mitigate the trade-off between growth and defense. Plant Cell. 2017;29:666-80. https://doi.org/10.1105/tpc.16.00931

17. Li X, Clarke JD, Zhang Y, Dong X. Activation of an EDS1mediated R-gene pathway in the snc1 mutant leads to constitutive, NPR1-independent pathogen resistance. Mol Plant Microbe Interact. 2001;114:1131-39. https://doi.org/10.1094/MPMI.2001.14.10.1131

18. Maekawa T, Kufer TA, Schulze-Lefert P. NLR functions in plant and animal immune systems: so far and yet so close. Nat Immunol. 2011;12:817-26. https://doi.org/10.1038/ni.2083
19. Palma K, Thorgrimsen S, Malinovsky FG, Fiil BK, Nielsen HB, Brodersen P, Hofius D, Petersen M, Mundy J. Autoimmunity in Arabidopsis acd11 is mediated by epigenetic regulation of an immune receptor. PLoS Pathog. 2010;6:1-14 https://doi.org/10.1371/annotation/c70c3fcc-01df-4f98-aa4f$19697 \mathrm{ccf} 7 \mathrm{cfa}$

20. Shirano Y, Kachroo P, Shah J, Klessig DF. A gain of function mutation in an Arabidopsis Toll Interleukin1 receptor nucleotide binding site-leucine-rich repeat type $\mathrm{R}$ gene triggers defense responses and results in enhanced disease resistance. Plant Cell. 2002;114:3149-62. https://doi.org/10.1105/tpc.005348

21. Halter T, Navarro L. Multilayer and interconnected posttranscriptional and co-transcriptional control of plant NLRs. $\begin{array}{llll}\text { Curr Opin } & \text { Plant } & \text { Biol. 2015;26:127-34 }\end{array}$ https://doi.org/10.1016/j.pbi.2015.06.014

22. Lai Y, Eulgem T. Transcript-level expression control of plant NLR genes. Mol Plant Pathol. 2017;19:1267-81. https://doi.org/10.1111/mpp.12607

23. Panigrahi GK, Satapathy KB. Arabidopsis DCP5, a decapping complex protein interacts with Ubiquitin-5 in the processing bodies. Plant Archives. 2020;20(1)2243-47.

24. Panigrahi GK, Satapathy KB. Formation of Arabidopsis Poly(A) Specific Ribonuclease associated processing bodies in response to pathogenic infection. Plant Archives. 2020;20(2):4907-12.

25. Panigrahi GK, Sahoo SK, Sahoo A, Behera S, Sahu S, Dash A Satapathy KB. Bioactive molecules from plants: a prospective approach to combat SARS-CoV-2. ADV TRADIT MED (ADTM). 2021;1-14. https://doi.org/10.1007/s13596-021-00599-y

26. Sahoo SK, Panigrahi GK, Sahoo A, Pradhan AK, Dalbehera A Bio-hydrothermal synthesis of $\mathrm{ZnO}-\mathrm{ZnFe} 2 \mathrm{O} 4$ nanoparticles using Psidium guajava leaf extract: Role in waste water remediation and plant immunity. Journal of Cleaner Production. 2021; 128522: 1-13. https://doi.org/10.1016/j.jclepro.2021.128522

\section{Additional information}

Peer review information: Plant Science Today thanks Sectional Editor and the other anonymous reviewers for their contribution to the peer review of this work.

Reprints and permissions information is available at https://horizonepublishing.com/journals/index.php/PST/open_access_policy

Publisher's Note: Horizon e-Publishing Group remains neutral with regard to jurisdictional claims in published maps and institutional affiliations.

To cite this article: Panigrahi G K, Sahoo A, Satapathy K B. Differential expression of selected Arabidopsis resistant genes under abiotic stress conditions . Plant Science Today. 2021;8(4):859-864. https://doi.org/10.14719/pst.2021.8.4.1213

Plant Science Today, published by Horizon e-Publishing Group, is covered by Scopus, Web of Science, BIOSIS Previews, Clarivate Analytics, etc. See https://horizonepublishing.com/journals/index.php/PST/indexing_abstracting 